\title{
Evaluating integrative services in edge-of-care work
}

\author{
Susan McPherson ${ }^{1}$, Leanne Andrews and Danny Taggart \\ School of Health and Social Care, University of Essex, Colchester, UK
}

Pamela Cox

Department of Sociology, University of Essex, Colchester, UK

Richard Pratt and Verity Smith

Parent Infant Mental Health Attachment Team, Norfolk and Suffolk NHS Foundation Trust, UK

Jasmeet Thandi

School of Health and Social Care, University of Essex, Colchester, UK.

This work was supported by the Transformational Challenge Fund through the Department of Communities and Local Government.

${ }^{1}$ Corresponding author: Susan McPherson, smcpher@essex.ac.uk 


\begin{abstract}
Children living on 'the edge-of-care' are typically known to local safeguarding authorities and are considered likely to face risks to their safety. Many are subject to a child protection plan and/or involved in 'pre-proceedings' processes. A growing number of their parents face (un)diagnosed mental health difficulties as well as economic and social precarity. This article draws on a mixed methods evaluation of a pilot service in the East of England offering a therapeutically-led attachmentbased intervention for families. The service cross-cuts health and social care, allowing psychologists and psychotherapists to work alongside social workers and other practitioners. The evaluation examined psychological and safeguarding outcomes and explored practitioner perspectives. A key outcome was that $85.4 \%$ of families were enabled to remain, or reunite with their child, compared with an estimated $50 \%$ of 'edge-of-care' cases nationally. This supports the need for similarly oriented interventions that could help lower the incidence of child removals.
\end{abstract}

Key words: attachment, therapeutic intervention, edge of care, recurrent care proceedings, parental mental health 


\section{Introduction}

There are no formal national figures on the high numbers of children living 'on the edge-ofcare'. However, according to the Department for Education (DfE), in 2016-7, there were 51,080 children subject to a child protection plan (CPP) and a further 32,810 who took on the status of a 'looked after child' (LAC) (DfE, 2017 ${ }^{\mathrm{a}}$; DfE, 2017 ${ }^{\mathrm{b}}$ ). The needs of these children have long been high on the political and social care agenda. Despite this, there is a growing concern that many of those needs still go unmet (Biehal, Cusworth, Wade \& Clarke, 2014; Munro, 2011). Established safeguarding services have often been reactive in nature and have often focused on meeting a child's needs once they have entered care proceedings rather than on more preventive measures (Munro, 2011). New preventive initiatives have been inspired by high profile social care serious reviews (Board, 2009; Laming, 2003), efforts to reduce the high number of LAC in England (DfE, 2015) and new measures to help parents break destructive cycles of recurrent care proceedings now estimated to account for up to a quarter of all public law care proceedings in England and Wales (Broadhurst et al, 2015; Cox et al, 2017; Pause, 2015).

Difficulties forming adult relationships, impairment in education and repeated foster care transitions are some of the growing difficulties facing children entering the care system (Minnis, Everett, Pelosi, Dunn \& Knapp, 2006). This, coupled with the increased financial costs of placing a child in care (Holmes \& McDermid, 2012) makes a strong case for considering interventions that prevent children from entering care in the first place whilst also addressing the potential risks associated with remaining with their birth families.

Efforts to pull families back from the 'edge of care' play an increasingly central role in policy and practice. Flagship initiatives such as Every Child Matters and the more contentious Troubled Families initiative (HM Government, 2003; Casey, 2012) were designed to improve children's life chances and reduce entries to the family and criminal justice systems. Legal reforms introduced in 2008 required family courts to hold 'preproceedings meetings' once care proceedings had been triggered (Jessiman, Keogh \& Brophy, 2009; Masson, Dickens, Bader \& Young, 2013) in an effort to identify ways of keeping families together where possible. Evaluation reports and reviews are helping to establish an evidence base around edge of care interventions, exploring, for example, parental capacity to change (Ward, Brown \& Hyde-Dryden, 2014), the development of solution focused approaches (Fernandes, 2015) and intensive interventions for children in such 
situations (Asmussen, Doolan \& Scott, 2012; Fox \& Ashmore, 2015). A study by Broadhurst, Doherty and Yeend (2013) on the effectiveness of early 'pre-proceedings' pilots has focused on their impact in reducing the duration of care proceedings and in strengthening kinship care options. New Family Drug and Alcohol Court services have pioneered new ways to lower child safeguarding risks by tackling parental substance misuse (Harwin, Alrouh, Ryan \& Tunnard, 2014). A number of interventions have developed nationally to work with women following the removal of children, in order to avoid future recurrent care proceedings, taking both an early intervention, pre-pregnancy approach and also targeting those most at risk of child removal (Cox et al, 2017; Pause 2015). A broader of range of evidence based interventions aimed at 'edge of care' families are identified in a recent literature review (Schradee-McMillan \& Barlow, 2017), including those which like the current study are aimed at enhancing attachment relationships and reducing risk of abuse. However, these interventions focus on problem-specific programmatic and therapeutic treatments, and there is an absence of evidence based service-level models with bespoke treatment plans for a broad range of familial and parental difficulties (Schradee-McMillan \& Barlow). It is this distinctive service level attachment theory orientation that is the focus of this study.

All these initiatives highlight family relationships as one of the most crucial influences on children's early lives and call for joined up services to strengthen these. Yet no evaluations to date have reported on the broader relationship-based and parent wellbeing outcomes for the families involved. There remains a need for research to support local service development for 'edge of care' work including evaluation of attachment-based approaches and exploration of the needs of parents facing mental health challenges.

The Norfolk Parent Infant Mental Health Attachment Project (PIMHAP) is a joint venture between Norfolk and Suffolk NHS Foundation Trust and Norfolk County Council. It became fully operational in 2015 and involves specialist mental health and children's services and consistent collaboration with the Children's Case Advisory Service which commissions packages of care for high need families. The project was commissioned to intervene with edge-of-care cases where there were significant safeguarding concerns alongside attachment problems in the parent-infant relationship and an identified parental mental health problem. Families were referred if there was a CPP or 'child in need' plan in place where there was significant risk of further deterioration. Significantly, two thirds $(63 \%)$ of the families engaging were 'recurrent' in that they had experienced the previous removal of at least one 
child, thereby making up a subsection of the national recurrent care population (Broadhurst et al, 2015). The majority resided in economically deprived neighbourhoods in Norfolk and could be described as leading 'precarious' lives.

Interventions were individually tailored and aimed to facilitate the development of a secure primary attachment relationship between parent and infant, to address need in the wider family system and to treat parental mental health problems. Families referred to the project presented with a range of multifaceted psychological, interpersonal, familial and social difficulties. A typical referral pathway might start with Children's Services operational managers and social workers identifying a family in need where there is a safeguarding concern for an infant (usually aged under 2 years) and parental mental health issues. Children's Services staff then discuss the family's situation in a psychologically-oriented consultation with the PIMHAP team. If PIMHAP accept the referral, they carry out an assessment, develop an attachment-based psychological formulation and then design a tailored multi-disciplinary intervention for the family. This could involve supported attendance at a Children's Centre; engagement with a Family Nurse Partnership or community psychiatric nurse; participation in a Video Interactive Guidance exercise; a community-based residential assessment; a mother-baby-foster placement; or admission to an inpatient mental health unit. If PIMHAP do not accept the referral, it will still offer ongoing psychological consultation and signpost to more appropriate services. A distinctive feature of the service is that it is therapeutically-led and attachment-based (Crittenden, 2006). The focus on referral for risk from a child protection perspective meant that parental mental health needs and attachment issues faced by infants were highly varied across the project and required bespoke rather than programmatic interventions.

This article presents a co-produced evaluation of the PIMHAP service based on 55 families referred to the service in the first year of operation. The aims were to evaluate the service in a number of ways. Specifically, to describe the histories and current context of the families referred to the service; to detail the interventions received by families; to examine changes in safeguarding status following engagement with the service with a view to estimating cost savings; to examine psychological wellbeing in the mothers engaging in the service with a view to assessing initial levels of psychological problems at referral as well as individual change; and finally to explore the experiences of health and care staff working within the service. 


\section{Methods}

\section{Quantitative methods}

A range of information relating to each family in the service was recorded including their histories and current context; the range of interventions delivered; and safeguarding status at referral and discharge.

Safeguarding status consisted of five categories: section 47 (child at risk of significant harm); section 17 (child in need); interim care order; looked after child (LAC); foster/kinship care or supported accommodation. Child outcome was also assessed by the service and consisted of five categories: remained with parents; extended family; foster placement; adoption plan; reunification plan. This data is presented descriptively. We also use data on changes in safeguarding status to calculate an estimate of cost savings generated by the service compared to usual practice.

In addition, psychological outcome measures were collected at the time of initial engagement (T1) and at 6 months after engagement (T2). These were three self-report questionnaires which asked parents to offer their own assessment of their situation and broader wellbeing in a way that could inform a clinical judgement of their therapeutic needs. Each of the three measures have good psychometric properties and have been used widely in research and practice which means there are published data available on general population and clinical population norms which enable the data in the current evaluation to be compared to other populations and services.

The Clinical Outcomes in Routine Evaluation (CORE-OM) covers a range of psychological difficulties within four domains of problems, risk, wellbeing and functioning (Evans et al, 2002).

The Difficulties in Emotion Regulation (DER) scale (Gratz \& Roemer, 2004) assesses six domains of non-acceptance of emotional response, difficulty in engaging in goal-directed behaviour, impulse control difficulties, lack of emotional awareness, limited access to emotion regulation strategies and lack of emotional clarity.

The Mothers Object Relations Scale (MORS) (Simkiss et al, 2013) measures the quality of the parent-child relationship and has two dimensions of warmth and invasion.

These psychological outcome measures were analysed in two ways: to provide a description of the severity of presenting issues at referral; and to examine individual changes between engagement and follow-up using clinically significant and reliable change indicators 
(Jacobsen \& Truax, 1991). This method enables analysis of individual change over time, taking into account statistical norms derived from clinical and community population norms. The analysis requires normative data from both community population samples and clinical samples which have some similarity to the population under study to compare against. Accordingly, community population norms were taken from Evans et al (2002) for the CORE; Ritschel, Tine, Schoemann \& Lim (2015) for the DER; and Milford and Oates (2009) for the MORS. Clinical sample norms were taken from Evans et al (2002) female sample for the CORE; Rowsell, MacDonald and Carter (2016) for the DER; and Coster, Brookes and Sanger (2015) for the MORS.

Because of the small number of cases where paired T1 and T2 data were available, we did not carry out group level analysis of change to find out whether, overall, families in the service improved or deteriorated after having engaged in the service (by looking at group averages). Instead we focus on individual level change.

\section{Qualitative methods}

Qualitative data was gathered to capture the views and experiences of professional staff involved in direct service delivery. The aim was to gain an operational and strategic view of staff experiences of an integrative health and social care initiative.

Three focus groups were undertaken, involving 24 members of multiagency staff groups. The groups took place, either prior to or following a regular fortnightly case review meeting in order to promote good attendance. In addition, seven social care staff (including social care managers and social workers) took part in individual interviews. The staff members that participated in the focus groups and interviews included PIMHAP mental health practitioners, PIMHAP enhanced therapists, the PIMHAP lead, trainee clinical psychologists, children's services managers, children's services social workers and assistant practitioners, children's centre managers, midwives, and allied project consultants and administrators.

Focus group and interview data were analysed following principles of thematic analysis (Braun \& Clarke, 2006). An inductive, data driven approach was taken as this was deemed to fit most clearly with the wider research question to gain an understanding of professionals' experiences of being involved in the PIMHAP project. 


\section{Quantitative findings}

\section{Family context and interventions}

In total, 55 families were referred into the service. About half of the families (45.5\%) had already been tracked antenatally by Children's Services. The mean age of mothers referred was 25.7years (range 15 to 45 years) and the mean age of the index child where the child had been born was 12.5 months (range 0 to 35 months). In $47.3 \%$ of cases, at the point of referral the mother was still pregnant with the index child. Table 1 provides details of the context and history of the families. Two thirds of parents $(63 \%)$ had already had at least one child removed from their care. Over two thirds of mothers (67\%) and $40 \%$ of fathers/current male partners were on prescription medication for a mental health condition. Nearly one fifth $(18 \%)$ had been admitted to psychiatric treatment in the past.

Families remained engaged with PIMHAP for an average of 10.1 months (range 317). Interventions consisted of contacts with PIMHAP core staff (psychologists and therapists) (mean 23.6 contacts, range 2-84) and adult psychiatry appointments (mean 1.1, range 0-6). Families also received auxiliary input as required (see Table 2). For example, one family were deemed to be placing their child at risk of emotional and physical harm because of domestic violence and other issues. They were offered, and accepted, an intervention based on principles of systemic family therapy designed to improve patterns of communication and a structured, attachment based parenting intervention to highlight their child's developmental needs. In contrast, another family were referred because the mother was assessed as having a learning disability and a consequential limited understanding of their child's more subtle emotional needs and cues. They were offered a video-based intervention to highlight microprocesses between the mother and baby, alongside a concrete parenting psycho-educational program to help the mother understand infant development. In all of the cases a tailored approach was used to respond to the particular risk factors and needs.

\section{Safeguarding status: referral and outcomes}

Safeguarding status and child outcomes were recorded pre- and post-intervention for the 55 families engaging with PIMHAP. A significant finding of this evaluation is that in $45.5 \%$ of these families the safeguarding risk status was lowered and in $27.3 \%$ it stayed the same; in 47 (85.4\%) of families, the index child remained with the parents or with extended family. In one family where a child had already been removed before entering the PIMHAP 
programme, a reunification plan was in place by the end of the intervention. In $7(12.7 \%)$ families, the child was removed to foster care or adoption. Tables 3 and 4 present detailed figures on safeguarding status at referral and discharge and child outcome.

This 'success' rate of $85.4 \%$ is higher than those on a regular CPP (50\%; see Woodman, 2017). This offers a means of making a cautious estimate of the financial savings offered by PIMHAP in terms of 'avoided costs' to the local authority. Under usual CPPs, $50 \%$ of PIMHAP families (28/55) might have stayed together; whereas 47/55 families actually stayed together, giving an added benefit to 19 families. It has been estimated that care proceedings cost a minimum of $£ 50,000$ per case (Cox et al, 2017), which would suggest that PIMHAP may have helped to save $£ 950,000$. Offsetting this against $£ 600,000$ service running costs means an overall saving of around $£ 350,000$.

\section{Psychological measures: wellbeing at referral}

Table 5 shows data on the CORE, MORS and DER for all mothers who completed the questionnaires at referral (T1). Means on the CORE indicate that the mothers entering the PIMHAP service reported mean scores in the low level range (0.6-1) for the total score as well as the functioning score. On average, mothers were in the mild band (1-1.5) which is considered to be within the clinical population on problems and wellbeing at referral. On average, mothers scored in the healthy range (0-0.6) on risk at referral.

We are unaware of specific clinical bands for MORS scores but we can compare scores from the NSPCC BabySteps programme (Coster, Brookes \& Sanger, 2015) which was for parents in need of additional support, including those who had been in the care system; who misused drugs or alcohol; who had been involved in crime or anti-social behaviour; gypsies or travellers; recent migrants, asylum seekers or refugees; victims of domestic violence; parents living in poverty; parents lacking strong social networks; or parents with low-level mental health problems. Parents in the BabySteps programme had a mean MORS warmth score of 21.16 which was slightly lower (worse) than mothers in PIMHAP; and mean a MORS invasion score of 6.2 which was similar to the PIMPAP mothers.

We are unaware of specific clinical bands for DER scores but in contrast with data from a clinical sample of females with eating disorders (Rowsell, MacDonald \& Carter, 2016), mothers' scores on all of the DER subscales appear to be relatively lower than a 
typical clinical population. For example, compare the mean total DER of 76.41 with the mean of 115.57 seen in the clinical sample of females with anorexia.

\section{Psychological measures: individual change}

Table 6 shows the indicators relating to clinically significant and reliable change across all of the psychological measures where paired data were available (data at T1 and at T2 for the same mother). As indicated in the table, paired data were available for 10 mothers on the MORS, 14 mothers on the CORE and 11 mothers on the DER. The effect size indicates the amount of change from $\mathrm{T} 1$ to $\mathrm{T} 2$ and the greatest amount of change (improvement) can be seen to occur on the MORS warmth scale (effect size 1.18). This is considered to be a large effect size. Effect sizes for other measures are small to moderate (-0.06 to -0.40). Improvement on the MORS warmth is also indicated by the number of participants (7) who 'improve' on the scale reliably compared to other scales which see only 2-4 participants improving. Table 7 presents the outcome according to the reliable and clinically significant change categories for each participant on each measure.

Mothers reported low levels of psychological disturbance overall but it is likely that clients were under-reporting emotional and psychological problems. The pattern of change on most psychological measures was mixed with individuals improving, deteriorating or staying the same on each measure in no particular pattern. Notable, however, is that the majority ( 7 out of 10) mothers improved on the MORS warmth scale; there is also a large effect size of 1.18 for the group mean change on MORS warmth suggesting a trend for mothers to feel or report more warmth towards their baby after 6 months of engagement with PIMHAP which suggests a potential lowering of risk.

Table 8 also presents details of safeguarding status and child outcome for individual cases where pre- and post- data on psychological measures were available. This family level data can be compared with the clinically significant and reliable change outcomes data presented previously.

\section{Qualitative findings}

Four main themes emerged from analysis of the practitioner interview data offering valuable insight into the experience of working within PIMHAP's new therapeutically-oriented service configuration: a safe place to leave professional defences behind; working within financial 
and professional constraints, creating solutions to long standing dilemmas, and holding really tough stuff without switching off.

\section{A safe place to leave professional defences behind}

This reflected the values and advantages of multi-agency joint working in terms of sharing perspectives, ideas, skills and understanding. It also included the importance of being able to come together and be reflective as well as the utility of holding different opinions. A key feature of the service was professionals from different disciplines and agencies discussing cases together which participants described as being both unique and central to success of the project owing to the opportunity it provided for learning from each other:

...[a] particular mix of people with particular therapeutic trainings, psychotherapy understanding in different forms, whether it's art, or other forms, psychology, psychiatry,...I've become far more aware of social work process through this and sometimes I think ... I might make a decent social worker, you know (collective laugh). Whereas before I would have never had thought that so I think we learn from one another but equally, I think it's important to know that success is linked to everybody

contributing...

I guess that thing around the joined up-ness, that linking together, that multi-agency working, that understanding more about what everyone else can do and how that links together, we all try to do that and we're all gradually getting better but...this is the only project which I've been involved with where that's integral to everything about the

project

Working with PIMHAP appeared to have impacted the social workers in their professional learning and development in that they had adopted some psychological ways of thinking about cases:

What I try to do is formulate now, hypothesise too. PIMHAP sessions have helped me think more holistically and opened me up to the therapeutic model. 
Respondents expressed their newfound interest in psychological theory and desire to learn more about it:

I've become interested in attachment theory and the intervention that could be done to support building secure attachment it's something I want to learn more about and take further.

It was suggested that one of the most unique aspects of PIMHAP was its theoretical grounding within attachment and systemic theories which meant that families were provided with a service unlike others in the local area.

It's such a well thought out and therapeutically led service. More services should have a clear theory underpinning it.

A children's centre manager discussed the influence on her team:

I think it's really helped ...upskill, certainly from my perspective because you know like you were just saying I'm always taking something back from this meeting and discussing this with my team, we changed the way that we deliver a lot of our support to families ... we're getting a much more in depth understanding of what's going on for those families, where their history comes from and so we might then go on to help them. So we're not setting them up with a programme of parenting courses or something that isn't going to work for them so it's much more kind of bespoke support for

families.

This also touches on the importance of developing a deeper understanding through meeting together, sharing skills and a joint endeavour to learn more about families' past experiences, using this to inform packages of support. Similarly, a specialist midwife noted the wider reach of sharing understanding with her colleagues:

As a midwife it's made me think more when I deal... with my colleagues. I'm talking more about bonding and attachment because as midwives it's ok to change the baby 
and feed the baby but no-one would actually look at how mum was reacting to the baby. So it's actually instilling that in the midwives on the ward, which I think has been

helpful.

This cross fertilisation of professional perspectives worked both ways. Psychologist voiced the importance of insights gained from social work agencies which could be less pathologising than in psychology settings:

...what I like about the children's centre was that it's possible to [just think about] points of human contact and human relationships. So families who within a mental health setting would be highly risky, high levels of complex personality disorder and mental health problems, in a children's centre were, mum and dad, and they've got two kids and they come along and it felt like there was less of a pathologising ethos.

The opportunity to hold multi-agency conversations was intended as a "reflective safe space" and the element of safety was noted as being key to enabling professionals to work therapeutically whilst holding high levels of risk.

[The] opportunity for the care and the attention and the really deep thought about the cases which I think in other sections of the NHS, the pace of that through-put prevents that, what feels at times like a luxury to have. But actually shouldn't be a luxury it should be an essential component of the work.

A dominant narrative iterated by social work respondents was that PIMHAP had afforded them with the space to reflect about the infant and family in a way which they previously had not done so. For some respondents this was also valuable on a personal level:

I now have an improved capacity to reflect and think about cases as well as my own life in a different way. 
I think as a social worker, sometimes you can get so bogged-down in the crises that are happening, but I think sometimes there's value in just kind of stopping and reflecting and PIMHAP certainly gives us an opportunity to do that.

Participants talked about a commitment which extended across agencies and across individual points of disagreement.

I feel I respect you and your teams more than a disagreement over one case so one case could never break us because I knew that we all came from, and that's about an underlying ethic, we all came from the same commitment to families.

Yet joined up thinking was not always easy. Staff noted being constrained by different training and differing expectations of court as reflected in the following theme 'working within financial and professional constraints'. In spite of, or because of those constraints, there was reference to needing courage to come together and talk about things when noticing the start of ruptures or splits in the professional system.

...one of the biggest challenges is trying to reach a shared understanding of risk and how we join... manage risk, in particular our relationship with children's services is something that's evolving and it takes a lot of almost courage on the part of all of us to reach that common understanding and real joined up thinking and planning about how we go forward because we're all constrained by our training and our expectations of the court but we're finding ...that is quite a challenge, is sometimes we come into conflict but I think we should regard those as opportunities, not times we all back away into our defensive corners but grab it and grapple with it and reach some understanding,

\section{Working within financial and professional constraints}

As noted above, working together within a diverse set of professional norms was at times challenging. Participants commented on feeling constrained or limited both by professional differences and by the external financial context.

The reality of limited financial and subsequent physical resources was keenly felt as limiting the aspirational goals of PIMHAP. Specifically, children's centre managers talked 
about the challenge of wanting to link in more closely with PIMHAP alongside managing reduced resource. There were challenges felt around time commitment to attend meetings as well as difficulties thinking about how PIMHAP extends capacity and continues to respond to need without any additional resource.

...that ... constant tension about undertaking long term work but also having the capacity to still ... be useful to the community and the families that are out there

...there's an expectation that we will be able to deliver much more widely... but that obviously had resource implications, we have the same amount of resource allocated just about so, how we're going to [do] that logistically we don't know but we would like to.

Going beyond surface level logistical barriers, there was a clear sense of ideological dilemmas and differences in working culture that had an impact on joint-working. The conceptualisation of risk, for example, was an important aspect of the data. Social workers highlighted that effective management of risk to the child was a core part of social work and they felt that the PIMHAP psychologists and therapists did not always share this level of risk scrutiny because they were too concerned with parental wellbeing:

Risk is the forefront of social workers' minds whereas PIMHAP work from the therapeutic perspective.

A key professional difference was in the concept of 'the client'. Whilst the general consensus was that social services deliver services with the child in mind, it was felt PIMHAP privileged the role of the family:

We focus on the child not the family, that's what's best for the child.

Some of the PIMHAP workers at times, over-identified with mum and I did feel, being completely open and honest with you, that was quite dangerous at times. 
Part of this conflict related to social workers and PIMHAP staff having different objectives, different perspectives on change and working in different time frames:

Although therapeutic staff don't mind seeing change over a longer period, social workers need to see immediate change, within 26 weeks.

We have a difference in views, PIMHAP may say 'yes mum is making progress, there is good attachment forming', we might say 'yes but she still cannot keep child safe'... different clients and different objectives, right?

Nevertheless, there was a sense that the PIMHAP staff became conscious of the dilemmas faced by the social care staff and could appreciate the challenges of working much more in a decision making role prioritising the child:

The thing it helped me with was getting beyond the stereotype of the social worker as being anti-parent. Because you can just see when they bring those cases how much they struggle with it. The morality of it, the ups and downs, trying to figure out how to do the best they can and the struggle the social worker has you really get a sense of it in that consultation because they have the time to really pour it all out and then how much you know them and [name] knows them, and you've known the family for 20 odd years.

There was however a sense that holding difference was also useful:

I think sometimes when you've got a difference of opinion and you do have differing discussions it sparks more thought.

Multi-agency conversations therefore appear to provide an opportunity for more constructive thought to emerge from different opinions. A participant noted the role of building relationships and creating a safe space as the first step towards being able to hold difference. 
I think the underlying respect for difference and valuing each other's expertise and to hopefully through building those relationships create a safe space where we can hold that difference. 


\section{Creating solutions to long standing dilemmas}

Perhaps through brining different perspectives together and professionals learning from each other, there was a sense that PIMHAP enabled fresh thinking and solutions to long-standing dilemmas in this field of work. Participants commented on the creativity of interventions which promoted individuals' professional skill sets as well as personal characteristics. Staff felt that the freedom and space to work in a way which they felt met families' presenting need was a key strength of the service. Participants talked about freedom to be flexible within the work and re-organise the nature of the intervention depending on the emerging needs within the family.

...there is a freedom and permission to be able to be in the moment and go with what you've got in the moment and then adapt and rethink and reorganise yourself and the work.

Participants also talked about the space families have to bring and share different experiences as opposed to being limited to working within a pre-determined structure. The capacity of PIMHAP to be responsive was noted as a valuable feature of the service, allowing families to receive help quickly, specifically in relation to adult psychiatry time.

The timeliness of access to different roles is probably key as well, because from a child development point of view if you wait eight weeks for a psychiatrist appointment and that's being really optimistic, that's eight weeks in a child's life and during those eight weeks that child's development can be affected in lots of different ways. From a social care point of view we have limits on decision making based around child development goals and expectations, so being able to offer solutions more quickly at the time the family needs them rather than within external frameworks for waiting means that we are likely more able to make the right decision at the right time rather than letting things drift and go terribly wrong.

Respondents commented on the ease and flexibility of the referral pathway compared to other mental health services they had accessed in the past. 
We refer, we discuss and they take the case on, it's really very simple compared to other mental health services.

This responsiveness was felt to be related to increased flexibility during the initial project phase but it was acknowledged that this would be more difficult to maintain as PIMHAP transitioned to a substantive service and that for some social workers there was a sense of confusion as to the 'right' type of case to refer.

I just refer all my cases where the parent has issues, even the unborn babies, I'm not sure if this is useful because they probably can't help them all, I don't know what they [PIMHAP] are looking for in a good case

A key feature in many respondents' narratives was the respect and admiration they held for the PIMHAP staff. This appeared to contribute greatly to their perception of PIMHAP effectiveness.

[They are] very skilled, highly qualified members of staff. We trust their judgment and respect their...their knowledge and their expertise their understanding and their work around attachment, I'm sure you cannot get better service in this area.

The importance of individual contributions that extend professional understanding and include the human aspects of working with families was also noted. In particular, participants' voiced the challenges of engaging with families who find trust difficult and the importance of individual staff skills in this context:

I think there's always been a recognition of ... as we were just saying, the skill mix, but also perhaps personalities or ... approaches that people use and so for one particular family, one practitioner ... really seems to fit and for another... so there's an understanding that this might not be the right person to work with this person and if that's not working then that's fine, we make it work for the family ..., because there has had to be a lot of creativity to get people to engage and I think that's really helped 


\section{Holding really tough stuff without switching off}

There was a clear felt impact of managing, working with and being held accountable for a high level of risk to infants and young children. Participants talked about vulnerability within families and some of the challenges of being involved therapeutically with families. The intensity of work clearly had an impact on staff through hearing about cases in clinical meetings:

...it was quite a tough morning for me, because you know, we have two hours of listening to some really tough stuff and ..., although again I think it's managed really well ... I do remember some of the times I was coming away thinking 'oh my goodness, what's going' you know that's really tough to then get on with your day job having listened to some quite tough crises that people are going through ..., I don't know, because I don't feel like that now, whether or not we are doing more of the containing thing within the group or..., maybe got more used to hearing the situations.

It seemed that a strength of the project was enabling staff to hold high levels of risk while still working in a therapeutic way:

The level of risk you carry though, is high, we [children's services] deal with these cases all of the time and I think we switch off in a way that's not helpful for us in lots of ways, but the fact that you've been able to manage that high level of risk and always keep a focus on the child but also on a parent therapeutically, whilst you're describing behaviours which can be quite damaging that must be horrible to watch so I think having come in and seen it you've held that well and from the outside it's looked incredibly honouring of children's and families' situations.

There was a clear sense that the type of families that the project worked with were characterised by difficulties with engagement, high levels of risk and vulnerability. While this meant that staff were keenly aware of the level of risk and difficulty they were working with, 
there was also a sense of pride, challenge, hope and inspiration in the opportunity to work differently to promote engagement and sustain relationships in highly difficult circumstances: It's just been so refreshing and inspiring to work with everybody and also to work in families' homes to me is so important all these hard to reach families that are so worried with major trust issues, to go right in there and get to form that relationship.

It's important to be aware about managing time but also..., some of these families because of the nature of them they might not be there when you turn up, you know taken half a day to get there and they're just not there.

There were elements of hope expressed by practitioners derived from seeing gains in spite of the level of difficulty in the families they were working with:

In the context of some of the families we are working with, in the organisations we work in, sometimes hope is in fairly short supply, and I think that there is a hope and it's not like cock-eyed optimism you know it's qualified, and I think there's a realism to the service but I think there's a hopefulness too and I think that's really good to be part of because I think, even when one doesn't know what the solution is but if there's an element of hope you're more likely to seek it out whereas if one becomes hopeless as an individual or as a service or as a family then ..., there isn't always a way out because you're bound by your lack of hope so yeah I would say that's a really big thing for me. And I would say as a year, last year was one of the best working years of my life, because of the things, I've found it tough in lots of ways, but it felt like I and people around me were doing the work we'd wanted to do for a long time so despite all the constraints and frustrations.

I think the whole experience for me has been you know so fascinating to see, the difference that PIMHAP project has made to families at keeping families together, especially the support from parents who probably didn't experience a great childhood themselves. You know, having that support from PIMHAP and turning things round to turn them into better parents themselves. 


\section{Discussion}

PIMHAP worked with 55 families during the first year of operation. They presented with complex histories of mental illness, parental trauma, histories of one or both parents being in care, about a third of families where drug or alcohol abuse has been present, a high rate of past domestic violence (84\%) and of particular note, $63 \%$ of families had had previous removals. These data indicate that the population being served by PIMHAP has high levels of complex needs, meeting the definition of edge of care but presenting in a range of ways that would make an 'off the shelf' intervention ineffective (Munro, 2011) thus requiring evidence based approaches to be applied idiosyncratically to each family (Woods, 2011).

The psychological measures suggest that on average, the sample of families seen in PIMHAP have low levels of psychological disturbance at referral. However, this does not correspond to the features of clients' histories or clinician reports which indicate likely psychological problems. Therefore it seems probable that clients were under-reporting emotional and psychological problems on the self-report measures. Where paired data were available for T1 and T2 (in 10-14 cases), the pattern of change was mixed with individuals improving, deteriorating or staying the same on each measure in no particular pattern, suggesting fairly random responding. The exception to this was the MORS where a clear pattern emerged. One possibility is that the MORS questions may be more difficult to second guess than the other questionnaires and may therefore reflect a more honest self-assessment. There was a clear pattern of improvement on the MORS warmth scale on which the majority (7 out of 10) mothers improved and the rest showed no change. There was a large effect size of 1.18 for the group mean change on MORS warmth pointing towards a trend for mothers to feel more warmth towards their baby after 6 months of engagement with PIMHAP. The issue of integrity in responding to self-report measures in a context in which mothers feel they are under intense scrutiny will need further investigation as it has a significant impact on the extent to which similar evaluations in social care can make use of self-report measures when families are subject to child protection proceedings. There were similar issues with self-report measures in two other social care intervention evaluation studies within the region (Granville, 2016; Cox et al, 2017).

The safeguarding outcomes indicate that $85.4 \%$ of families engaging with PIMHAP were enabled to remain with or reunite with their child and that there was an overall trend towards lowering of safeguarding risk status. This is significant, given that only an estimated 
$50 \%$ of parents with children subject to regular child protection plans (CPP) go on to remain or reunite with their child (see Woodman, 2017) and given that parents - like $60 \%$ of the PIMHAP parents - who have already lost one child to care are much more likely to lose subsequent children in the same way (Broadhurst et al, 2015). Although we recognise that the sample of 55 in this evaluation is small and that comparing this to national data must be done with caution, we have estimated that the service may have helped to save $£ 350,000$. These estimated savings need to be considered alongside the perhaps incalculable value of the 'intangible benefits' - emotional, psychological and relational - experienced by many of the engaging parents and children. In the absence of both a control group and formal national statistics on the 'flow' of children from 'edge-of-care' to full child protection, this estimate should of course be treated with caution. That said, this finding supports emergent work in this field that suggests that many parents do have the capacity to change, even when their children are on the edge of care (Ward, Brown and Hyde-Dryden, 2014) and that intensive interventions' (Bowyer, 2009) of the kind offered by PIHMAP offer an effective way forward. It also contributes to a much-needed evidence base to shape the safeguarding of children on the edge of care (Welbourne, 2011).

In offering a longer-term attachment based intervention, PIMHAP sits in contrast to the short-term behavioural based sensitivity treatment recommended by NICE (2015) for attachment problems. However, given the integrated service model and high level of risk it is difficult to see how a short-term intervention could have been trusted sufficiently by Children's Services to reduce child protection status. Therefore, the relational, attachmentbased approach of PIMHAP functioned not only to engender change through therapeutic relationships at the familial level, but attempted to do the same at an inter-agency level. It is recommended that future edge of care interventions pay the same attention to the relational context of inter-agency working irrespective of length of intervention.

Findings from the focus groups and interviews highlighted the beneficial aspects of joint working, sharing skills and understanding and the importance of good communication between professionals. This is in keeping with existing research, which highlights effective communication as a key facilitator in effective joint working practices (Cameron \& Lart, 2003). More specifically, this echoes the recommendations proposed by many of the seminal children's policies (Children's Act 2004; Every Child Matters, 2003). The development of thinking using attachment theory and reflective safe spaces was also noted as key and this 
relates to the recommendation in the Social Work Reform (Department for Education, 2010), which advocates for social workers to shift from analytical reasoning to an increased awareness of their intuitive and internal processes as well as recommendations from a social work review (Turney, Platt, Selwyn \& Farmer, 2011) which encourages social workers to embrace the individuality of the child and pay close attention to their individual context, akin to a psychological formulation. In addition, 'signs of safety' approaches (Bunn, 2013), combining identification of risks with identification of strengths and foundations for change, were influential in the conceptual development of PIMHAP. Overall, the PIMHAP model of joint working across health and social care with families in a transparent, strengths-based way complements new approaches to managing risk.

However, while respondents placed emphasis on effective communication as a means for delivering high quality of care, the findings also provided an insight into barriers which can hinder communication. Challenges to joint working are particularly highlighted in the theme

'working within financial and professional constraints'. These findings may be useful to inform policies in terms of how to circumvent potential barriers to effective joint working.

There were clear tensions evident in terms of the primary difference between social care and psychological approaches in which the former is perceived to have primary responsibility for the child and the latter perceived to have primary responsibility for the mother, often leading to discrepant views of the best way forward for a family. This perceived core difference appeared to be a source of tension and difference for practical as well as ideological reasons. There was a sense however that this polarized view could become less polarized through the joint working process. A number of respondents did speak about not having a clear idea of the roles and remits of therapeutic work and equally PIMHAP team members of not always being aware of the nuances of social work. However, this difference seemed to become less stark through sharing of skills and understanding and potentially to hold some useful potential for cross-fertilization of thinking and an emergent dialectic of practices. Another feature of PIMHAP that aimed to reduce the gap was through the relational focus of attachment theory (Schore \& Schore, 2008). From a conceptual perspective, the PIMHAP team were aiming to treat the relationship between the parents and the infant, therefore avoiding any either/or alignment. Communicating this relational focus effectively and consistently to Children's Services colleagues is likely to be a feature of 
future success, possibly through links to the influence of relational theory on social work practice (Saari, 2005). From a social care perspective, the binary thinking evidenced in the parent-child distinction here can be seen as part of a wider issue regarding differing philosophies of decision making about risk in Child Protection. Houston (2014) calls for a methodological pluralism that combines more objective, actuarial analyses of risk while attending to 'meaning making' processes of parents and clinicians in relationship with one another and children. This methodological pluralism, emphasizing both objective and subjective measures of change, fit well with the integrated approach of social care and therapeutic worldviews espoused by PIMHAP, the finding of this study suggests that this 'method triangulation' (Houston, 2014) is possible but tends towards disintegration under pressure.

The positive views about the conceptual distinctness of PIMHAP adds to the relatively limited evidence base for longer term attachment-based interventions. However, it is also evident that the many positive features of the service as perceived by professionals constitute a complex combination of factors including but not specifically the mode of treatment itself. The positive features include a manner of joint agency working, a multidirectional transfer of skills and understanding and the provision of spaces for reflective work which enhances staff practices, protects staff from the intensity of the work and potentially benefits the clients. Therefore, it is the way in which attachment principles of a relational psychology, the building of a secure base from which to share learning and higher order meta-cognitive processing were infused through all aspects of the PIMHAP delivery and contributed towards its distinctiveness. It is this service level intervention that attempts to embed attachment principles into all relevant relationships, including that between services and staff, that distinguishes this study from other evidence in the field (Schrader-McMillan \& Barlow, 2017) and points to the need for future research considering how to enable integration at a systems level in order to congruently facilitate integration for families at the edge of care.

\section{Conclusion}

This evaluation has used quantitative and qualitative methods to evaluate a new therapeutically-oriented integrative service for edge-of-care families. It suggests that this preventive intervention is effective at a number of levels. A large proportion $(85.4 \%)$ of 
families stayed together and reduced their safeguarding risk status following six months engagement. The service may be particularly helpful in terms of increasing and capturing mothers' feelings of warmth towards their baby. While this may be related to response bias, it does indicate a key area for further attachment-based work with this population. Since all the infants involved were deemed to be at risk of removal, these findings indicate that the service has helped to allay professionals' collective concerns about the majority of their families and helped to pull them back from the edge-of-care. Overall, the evaluation suggests that therapeutically-led integrative services like PIMHAP have much to offer and should be expanded.

\section{References}

Asmussen, K., Doolan, M., \& Scott, S. (2012). Intensive interventions suitable for Children on the Edge of Care: report and recommendations for Social Finance. London: National Academy for Parenting Research.

Biehal, N., Cusworth, L. S., Wade, J., \& Clarke, S. E. (2014). Keeping children safe: allegations concerning the abuse or neglect of children in care. London: NSPCC.

Board, H. L. S. (2009). Serious case review: Baby Peter. Executive summary. Retrieved on June $1^{\text {st }}$ 2016: Available online at www. haringeylscb. org/executive_summary_peter_final. pdf.

Bowyer, S. (2009) Children on the Edge of Care: Intensive Family Preservation Services and Family Intervention Projects, Dartington: Research in Practice.

Braun, V. \& Clarke, V. (2006). Using thematic analysis in psychology. Qualitative research in psychology, 3(2), 77-101.

Broadhurst, K., Doherty, P., and Yeend, E. (2013) Coventry and Warwickshire PreProceedings Pilot, Final Research Report. 
https://www.cafcass.gov.uk/media/167143/coventry_and_warwickshire_preproceedings_pilot_final_report_july_4_2013.pdf

Broadhurst, K., Alrouh, B., Yeend, E., Harwin, J., Shaw, M., Pilling, M... \& Kershaw, S. (2015). Connecting events in time to identify a hidden population: birth mothers and their children in recurrent care proceedings in England. British Journal of Social Work. 45 (8), 2241-2260.

Bunn, A. (2013). Signs of Safety in England: An NSPCC commissioned report on the Signs of Safety model in child protection. London: NSPCC

Cameron, A., \& Lart, R. (2003). Factors promoting and obstacles hindering joint working: a systematic review of the research evidence. Journal of Integrated Care, 11(2), 9-17.

Casey, L. (2012). Listening to Troubled Families. London: Department for Communities and Local Government.

Coster, D., Brookes, H. \& Sanger, C. (2015). Evaluation of the baby steps programme: pre and post measures study. London: NSPCC

Cox, P., Barratt, C., Blumenfeld, F., Rahemtulla, Z., Taggart, D. and Turton, J. (2017). Reducing recurrent care proceedings: initial evidence from new interventions. Journal of Social Welfare and Family Law, 39(3), 332-349.

Crittenden, P.M. (2006). Why do inadequate parents do what they do? In O. Mayseless (Ed.), Parenting representations: Theory, research, and clinical implications (pp. 388-433). Cambridge: Cambridge University Press.

Department for Education. (2010). Building a safe and confident future: progress report from the social work reform board. Available at:

https://www.gov.uk/government/publications/building-a-safe-and-confident-future-progressreport-from-the-social-work-reform-board 
Department for Education (2015). 2010 to 2015 government policy: looked-after children and adoption. London.

Department for Education (2017a). Children looked after in England including adoption: 2016-2017. London.

Department for Education (2017b). Characteristics of children in need 2016-2017. London.

Evans, C., Connell, J., Barkham, M., Margison, F., McGrath, G., Mellor-Clark, J. \& Audin, K. (2002). Towards a standardised brief outcome measure: Psychometric properties and utility of the CORE-OM. British Journal of Psychiatry, 180, 51-60.

Fernandes, P. (2015). Evaluation of the Face to Face service: Using a solution focused approach with children and young people in care or on the edge of care. London: NSPCC.

Fox, S. \& Ashmore, Z. (2015) Multisystemic Therapy as an Intervention for Young People on the Edge of Care. British Journal of Social Work, 45 (7), 1968-1984.

Granville, S (2016). A qualitative inquiry of clinicians' relational experiences within a perinatal infant mental health service contextualised with quantitative analysis of outcomes (unpublished doctoral dissertation). University of Essex, UK.

Gratz, K. L., \& Roemer, L. (2004). Multidimensional assessment of emotion regulation and dysregulation: Development, factor structure, and initial validation of the Difficulties in Emotion Regulation Scale. Journal of Psychopathology and Behavioral Assessment, 26, 4154.

Harwin, J., Alrouh, B., Ryan, M., Tunnard, J. (2014). Introducing the main findings from: Changing Lifestyles, Keeping Children Safe: an evaluation of the first Family Drug and Alcohol Court (FDAC) in care proceedings. London: Brunel University Press. 
Holmes, L., \& McDermid, S. (2012). Understanding costs and outcomes in child welfare services: a comprehensive costing approach to managing your resources. Jessica Kingsley Publishers.

Houston, S. (2014). Meta-theoretical paradigms underpinning risk in child welfare: towards a position of methodological pluralism. Children and Youth Services Review, 47, 55-60.

HM Government. (2003). Every Child Matters. London: The Stationery Office.

Jacobson, N. S., \& Truax, P. (1991). Clinical significance: A statistical approach to defining meaningful change in psychotherapy research. Journal of Consulting and Clinical Psychology, 59, 12-19.

Jessiman, P., Keogh, P. and Brophy, J. (2009). An early process evaluation of the Public Law Outline in family courts. Ministry of Justice Research Series 10/09.

Laming, H. (2003). The Victoria Climbié Inquiry. Available at:

https://www.gov.uk/government/uploads/system/uploads/attachment_data/file/273183/5730.p $\underline{\mathrm{df}}$

Masson, J.M, Dickens, J., Bader, K., Young, J. (2013). Partnership by law? The preproceedings process for families on the edge of care proceedings. Available at:http://dx.doi.org/10.2139/ssrn.2281146

Milford, R. \& Oates, J. (2009). Universal screening and early intervention for maternal mental health and attachment difficulties. Community Practitioner, 82(8), 30-33.

Minnis, H., Everett, K., Pelosi, A. J., Dunn, J., \& Knapp, M. (2006). Children in foster care: Mental health, service use and costs. European child \& adolescent psychiatry, 15(2), 63-70.

Munro, E. (2011). The Munro review of child protection: final report: A child-centred system. London: Department for Education. 
NICE (2015). Children's Attachment: Attachment in Children and Young People Who Are Adopted from Care, in Care or at High Risk of Going into Care. London: National Institute for Health and Care Excellence: Clinical Guidelines.

Pause (2015). Pause: Creating Space for Change, National Launch Conference briefing. Unpublished report.

Ritschel,L.A., Tone, E.B., Schoemann, A.M. \& Lim, N.E. (2015). Psychometric properties of the Difficulties in Emotion Regulation Scale across demographic groups. Psychological Assessment, 27(3), 944-954.

Rowsell, M., MacDonald, D.E. \& Carter, J.C. (2016). Emotion regulation difficulties in anorexia nervosa: associations with improvements in eating psychopathology. Journal of Eating Disorders, 4, 17.

Saari, C. (2005) The Contribution of Relational Theory to Social Work Practice. Smith College Studies in Social Work, 75(3), 3-14.

Schore, J.R. \& Schore, A.N. (2008). Modern Attachment Theory: The Central Role of Affect Regulation in Development and Treatment. Clinical Social Work Journal, 36, 9.

Schrader-McMillan, A. \& Barlow, J. (2017). Improving the effectiveness of the child protection system: A review of the literature. Early Intervention Foundation.

Simkiss, D.E., MacCallum, F., Fan, E.E.Y., Oates, J.M., Kimani, P.K. \& Stewart-Brown, S. (2013). Validation of the mothers' object relations scales in 2-4 year old children and comparison with the child-parent relationship scale. Health and Quality of Life Outcomes, $11,49$.

Turney, D., Platt, D., Selwyn, J., \& Farmer, E. (2011). Social work assessment of children in need: What do we know? Messages from research. London: Department for Education. 
Ward, H., Brown, R., \& Hyde-Dryden, G. (2014). Assessing Parental Capacity to Change when Children are on the Edge of Care: an overview of current research evidence. Department for Education: Loughborough University.

Welbourne, P. (2008) Safeguarding Children on the Edge of Care: Policy for Keeping Children Safe after the Review of the Child Care Proceedings System, Care Matters and the Carter Review of Legal Aid. Child and Family Law Quarterly, 20(3), 335-358.

Woodman, J. (2017). Personal communication from Dr Woodman at Thomas Coram Research Unit, based on DfE data (2017a and 2017b above) and other literature including http://www.sciencedirect.com/science/article/pii/S0145213416302708

Woods, K., Bond, C., Humphrey, N., Symes, W. (2011). Systematic Review of Solution Focused Brief Therapy (SFBT) for children and families. Department for Education. London. 
Table 1: Family context and history

\begin{tabular}{|l|l|}
\hline Father (43.6\%) or partner (5.4\%) involved in intervention & $49.0 \%$ \\
\hline Biological father involved with child (even if not involved in intervention) & $60.4 \%$ \\
\hline New partner involved with child & $5.6 \%$ \\
\hline Mothers using prescription medication for mental health & $67.4 \%$ \\
\hline Father/current partner using prescription medication for mental health & $40.0 \%$ \\
\hline Either parent has a history of inpatient psychiatric admission & $18.0 \%$ \\
\hline Previous domestic violence known to service & $84.0 \%$ \\
\hline Current domestic violence known to service & $2.0 \%$ \\
\hline Father/current partner with history of being in care & $33.3 \%$ \\
\hline Mother with history of being in care & $36.2 \%$ \\
\hline Previous child removals (either parent) & $63.0 \%$ \\
\hline Father/current partner currently abusing substances or alcohol & $27.3 \%$ \\
\hline Father/current partner history of abusing substances or alcohol (not current) & $31.8 \%$ \\
\hline Mother currently abusing substances or alcohol & $19.2 \%$ \\
\hline Mother history of abusing substances or alcohol (not current) & $36.5 \%$ \\
\hline
\end{tabular}


Table 2: Auxillary interventions and assessments

\begin{tabular}{lll}
\hline Intervention & Number & Percent \\
\hline Adult Mental Health services (non-PIMHAP) & 18 & $32.7 \%$ \\
\hline Admission to inpatient psychiatric unit & 9 & $18.0 \%$ \\
Family Nurse Partnership involved & 5 & $9.4 \%$ \\
Video Interactive Guidance received & 19 & $34.5 \%$ \\
Residential assessment & 10 & $19.6 \%$ \\
Children's Centre attendance & 40 & $83.3 \%$ \\
Mother and baby foster placement & 6 & $11.3 \%$ \\
\hline
\end{tabular}

Table 3: Safeguarding status at referral and discharge (all cases)

\begin{tabular}{lllll}
\hline Safeguarding status & N at referral & \% at referral & N at discharge & \% at discharge \\
\hline Section 47 & 35 & $63.6 \%$ & 10 & $18.5 \%$ \\
Section $\mathbf{1 7}$ & 16 & $29.1 \%$ & 11 & $20.4 \%$ \\
Interim care order & 2 & $3.6 \%$ & 6 & $11.1 \%$ \\
LAC & 1 & $1.8 \%$ & 2 & $3.7 \%$ \\
Foster/kinship care/FSP/supported accommodation & 1 & $1.8 \%$ & 9 & $16.8 \%$ \\
No longer on safeguarding & NA & NA & 16 & $29.6 \%$ \\
\hline
\end{tabular}


Table 4: Child outcome (all cases)

\begin{tabular}{lll}
\hline Child outcome & N & \% \\
\hline Remained with parents & 41 & $74.5 \%$ \\
Extended family & 6 & $10.9 \%$ \\
Foster placement & 5 & $9.1 \%$ \\
Adoption plan & 2 & $3.6 \%$ \\
Reunification plan & 1 & $1.8 \%$ \\
\hline
\end{tabular}


Table 5: Mean scores for mothers' wellbeing at referral

\begin{tabular}{|l|c|l|l|l|l|}
\hline & \multicolumn{7}{|l|}{ Time 1 (Referral) } \\
\hline & $\mathbf{N}$ & Minimum & Maximum & Mean & SD \\
CORE-OM Total & 31 & 0.06 & 2.97 & 0.97 & 0.79 \\
CORE-OM Functioning & 31 & 0 & 2.75 & 0.93 & 0.80 \\
CORE-OM Problems & 31 & 0 & 3.17 & 1.21 & 0.95 \\
CORE-OM Risk & 31 & 0 & 3.50 & 0.25 & 0.66 \\
CORE-OM Wellbeing & 31 & 0 & 3.50 & 1.47 & 1.11 \\
MORS Warmth & 25 & 20 & 35 & 27.72 & 5.81 \\
MORS Invasion & 27 & 1 & 26 & 6.56 & 5.39 \\
DER Total & 23 & 37 & 134 & 76.41 & 32.65 \\
DER non-accept & 23 & 0 & 30 & 11.96 & 7.58 \\
DER goals & 23 & 5 & 24 & 11.95 & 6.04 \\
DER impulse & 23 & 6 & 23 & 11.00 & 4.83 \\
DER emotional awareness & 23 & 6 & 28 & 16.22 & 7.13 \\
DER strategies & 23 & 8 & 33 & 16.25 & 9.09 \\
DER emotional clarity & 23 & 5 & 21 & 9.04 & 4.54 \\
\hline
\end{tabular}

Note: CORE-OM - Clinical Outcomes in Routine Evaluation; MORS - Mothers Object Relations Scale; DER - Difficulties in Emotional Regulation; non-accept - non-acceptance of emotional response; goals - difficulty in engaging in goal-directed behaviour; impulse impulse control difficulties; emotional awareness - lack of emotional awareness; strategies - limited access to emotion regulation strategies; emotional clarity - lack of emotional clarity. 
Table 6: Clinically significant and reliable change indicators for psychological measures

\begin{tabular}{|c|c|c|c|c|c|c|c|c|c|c|}
\hline & $\begin{array}{l}\text { MORS } \\
\text { warmth }\end{array}$ & $\begin{array}{l}\text { MORS } \\
\text { invasion }\end{array}$ & $\begin{array}{l}\text { CORE } \\
\text { Total }\end{array}$ & $\begin{array}{l}\text { DER } \\
\text { sum }\end{array}$ & $\begin{array}{l}\text { DER } \\
\text { aware }\end{array}$ & $\begin{array}{l}\text { DER } \\
\text { clarity }\end{array}$ & $\begin{array}{l}\text { DER } \\
\text { goals }\end{array}$ & $\begin{array}{l}\text { DER } \\
\text { impulse }\end{array}$ & $\begin{array}{l}\text { DER } \\
\text { nonaccept }\end{array}$ & $\begin{array}{l}\text { DER } \\
\text { strategies }\end{array}$ \\
\hline Sample size & 10 & 10 & 14 & 11 & 11 & 11 & 11 & 11 & 11 & 11 \\
\hline Mean at Time 1 (referral) & 24.80 & 6.40 & 0.92 & 68.25 & 14.64 & 8.55 & 9.73 & 9.27 & 9.82 & 14.43 \\
\hline Time 1 SD & 4.66 & 4.33 & 0.79 & 31.21 & 7.85 & 3.83 & 5.75 & 3.20 & 5.86 & 9.46 \\
\hline Time 2 mean & 30.30 & 5.70 & 0.82 & 71.00 & 16.82 & 10.09 & 10.73 & 9.45 & 9.64 & 14.27 \\
\hline Time 2 SD & 4.60 & 4.52 & 0.60 & 24.82 & 7.81 & 4.23 & 4.96 & 4.66 & 3.53 & 5.41 \\
\hline Pre-post Effect Size & 1.18 & 0.16 & 0.12 & -0.09 & -0.28 & -0.40 & -0.17 & -0.06 & 0.03 & 0.02 \\
\hline \multicolumn{11}{|l|}{ Reliable Change Index } \\
\hline $\begin{array}{l}\text { Standard Error of } \\
\text { Measurement }\end{array}$ & 1.47 & 1.37 & 0.19 & 7.64 & 3.33 & 1.71 & 2.07 & 1.36 & 1.85 & 3.14 \\
\hline RCI value & 4.09 & 3.79 & 0.54 & 21.19 & 9.23 & 4.75 & 5.74 & 3.76 & 5.14 & 8.70 \\
\hline Number "No change" & 3 & 6 & 7 & 5 & 6 & 5 & 7 & 8 & 8 & 8 \\
\hline Number "Deteriorate" & 0 & 2 & 3 & 3 & 3 & 4 & 2 & 1 & 1 & 1 \\
\hline Number "Improved" & 7 & 2 & 4 & 3 & 2 & 2 & 2 & 2 & 2 & 2 \\
\hline $\begin{array}{l}\text { Number meeting clinically } \\
\text { significant change criterion }\end{array}$ & 0 & 2 & 4 & 2 & 2 & 2 & 2 & 2 & 2 & 0 \\
\hline
\end{tabular}

Table 7: Clinically significant and reliable change outcomes by participant

\begin{tabular}{|l|l|l|l|l|l|l|l|l|l|l|}
\hline ID & CORE & MORS & MORS & DER & DER & DER & DER & DER & DER & DER \\
\hline
\end{tabular}




\begin{tabular}{|l|l|l|l|l|l|l|l|l|l|l|}
\hline & & Warmth & Invasion & Aware & Clarity & Goals & Impulse & Non accept & Strategies & Sum \\
\hline 1 & Improve & & & & & & & & \\
\hline 2 & No change & & & No change & No change & No change & No change & No change & No change & No change \\
\hline 3 & No change & No change & Deteriorate & No change & Deteriorate & Deteriorate & Deteriorate & No change & Deteriorate & Deteriorate \\
\hline 4 & Deteriorate & Improve & Improve & Improve & Improve & No change & No change & No change & No change & No change \\
\hline 5 & No change & Improve & No change & No change & No change & Improve & Improve & Improve & Improve & Improve \\
\hline 6 & No change & Improve & Improve & Deteriorate & Deteriorate & Deteriorate & No change & No change & No change & Deteriorate \\
\hline 7 & Deteriorate & Improve & No change & No change & Deteriorate & No change & No change & Deteriorate & No change & Deteriorate \\
\hline 8 & Deteriorate & & & No change & No change & No change & No change & No change & No change & No change \\
\hline 9 & No change & No change & No change & Deteriorate & Deteriorate & No change & No change & No change & No change & No change \\
\hline 10 & No change & No change & No change & No change & No change & No change & No change & No change & No change & No change \\
\hline 11 & Improve & Improve & No change & Deteriorate & No change & No change & No change & Improve & Improve & Improve \\
\hline 12 & Improve & Improve & Deteriorate & & & & & & & \\
\hline 13 & No change & Improve & No change & & Improve & Improve & Improve & Improve & No change & No change \\
\hline 14 & Improve & & & Improve \\
\hline
\end{tabular}


Table 8: Safeguarding status and child outcomes (cases with psychological measure data)

\begin{tabular}{|l|l|l|l|}
\hline ID & Safeguarding (at referral) & Change to safeguarding level & Child outcome \\
\hline 1 & Section 17 & Reduced & Remained with parents \\
\hline 2 & Section 47 & Reduced & Remained with parents \\
\hline 3 & Section 47 & Reduced & Remained with parents \\
\hline 4 & Section 47 & Increased & Adoption plan \\
\hline 5 & Section 47 & Reduced & Remained with parents \\
\hline 6 & Section 47 & Reduced & Remained with parents \\
\hline 7 & Section 47 & Reduced & Remained with parents \\
\hline 8 & Section 47 & Reduced & Remained with parents \\
\hline 9 & Section 47 & Stayed the same & Remained with parents \\
\hline 10 & Section 47 & Reduced & Remained with parents \\
\hline 11 & Section 17 & Increased & Remained with parents \\
\hline 12 & Section 47 & Reduced & Remained with parents \\
\hline 13 & Section 47 & Stayed the same & Remained with parents \\
\hline 14 & Section 47 & Reduced & Remained with parents \\
\hline
\end{tabular}

